\title{
Effect of arbuscular mycorrhizal fungi and rhizobacteria on banana growth and nutrition
}

\author{
Ana Sue RodrígueZ-Romero*, María Sol Piñero Guerra, María del Carmen JAIZMe-VegA \\ Dpto. Protección Vegetal, Instituto Canario Investigaciones Agrarias, Apdo. 60. 38200. La Laguna, Tenerife, Spain
}

(Accepted 25 April 2005)

\begin{abstract}
The effect of the combined inoculation of the arbuscular mycorrhizal fungus Glomus manihotis and a rhizobacteria consortium of Bacillus spp. on micropropagated banana plantlets, during the acclimatization phase under routine nursery conditions was investigated. Micropropagated banana plantlets from the 'Grande Naine' cultivar were inoculated with $G$. manihotis at the beginning of the nursery phase. Twenty days after fungal inoculation, a Bacillus consortium containing approximately $10^{8} \mathrm{CFU}$ (colonies former units) $\mathrm{mL}^{-1}$ was applied. Plants were harvested $4 \frac{1}{2} 2$ months after bacterial inoculation. Combined application of mycorrhizal fungus and rhizobacteria significantly increased plant growth and nutrition. Combined inoculated plants showed growth parameters, i.e. total fresh weight, aerial dry weight, shoot length and leaf area, significantly higher than non-treated control bananas. Leaf mineral content, i.e. N, P and K, was also significantly increased following combined application of both microorganisms. No adverse effect on mycorrhizal colonization due to Bacillus spp. inoculation could be detected. Our results demonstrate that the combined application of arbuscular mycorrhizal fungi and plant growth-promoting rhizobacteria highly benefits banana plants and therefore could be considered during the acclimatization stage of micropropagated banana.
\end{abstract}

Glomus / Bacillus / micropropagated banana / growth / nursery phase / nutrition

\section{INTRODUCTION}

Micropropagation is nowadays a successful technique used to establish mass-production of plants for commercial and research purposes (Nowak, 1998). Among the plants currently propagated in vitro, bananas are increasingly replacing conventional planting material for the establishment of new or replacement of existing plantations. The reasons for using such material may be summarized by the rapid multiplication and production of high quality, disease-free, uniform plants. Nevertheless, micropropagated plants present some inconveniences such as more probability of somaclonal variations (reviewed by Damasco et al., 1998), poor physiology (George, 1996) and the lack of soil microbiota. It is well accepted that for most micropropagated crops, acclimatization, i.e. the weaning phase, is the most critical period in the micropropagation process (Vestberg et al., 2002). Symbiotic organisms such as arbuscular mycorrhizal fungi (AMF) and plant growth-promoting rhizobacteria (PGPR) are known to play a fundamental role in sustainable agroecosystems, improving plant performance under environmental stress conditions (Smith and Read, 1997; Nowak, 1998) and may facilitate plant adaptation to the nursery (reviewed by Rai, 2001).

Arbuscular mycorrhiza fungi (AMF) are obligate symbionts that colonize the roots of most cultivated plant species. Mycorrhizal symbiosis are found in nearly all types of ecological situations and most plant species are able to form this symbiosis naturally (Smith and Read, 1997). This association, which normally occurs naturally when plantlets are transplanted into the field, favors plant establishment, enhancement of nutrient uptake and protection against cultural and environmental stresses (Barea et al., 1997).

Plant growth-promoting rhizobacteria (PGPR) are able to colonize the root surface, survive and multiply in microhabitats associated with the root surface and promote plant growth (Kloepper, 1996). Their positive effects on plant development or establishment of seedlings have been described for different herbaceous and woody crop species (Polonenko et al., 1987; Caesar and Burr, 1987). Other important contributions such as protection against soilborne plant pathogens or nutrient cycling have been attributed to plant growth-promoting rhizobacteria (reviewed by Barea et al., 2002). Authors have frequently described some strains belonging to Bacillus, Pseudomonas, Azospirillum, Azotobacter, Enterobacter and Serratia (Kloepper, 1992) as plant growth-promoting rhizobacteria.

Arbuscular mycorrhizal fungi and plant growth-promoting rhizobacteria have been shown to interact during their processes of root colonization. Soil microorganisms, particularly plant growth-promoting rhizobacteria, can influence arbuscular mycorrhizal formation and function and consequently, mycorrhizas can affect plant growth-promoting rhizobacteria populations in the rhizosphere (reviewed by Barea et al., 2002).

\footnotetext{
* Corresponding author: arguezr@icia.es
} 
Relationships between both types of microbes are under high specificity rules (Azcón, 1989; Kloepper, 1996).

Work on the application of either arbuscular mycorrhizal fungi or plant growth-promoting rhizobacteria on micropropagated banana has demonstrated benefits in terms of plant development and nutrient uptake (Jaizme-Vega et al., 2003; Jaizme-Vega et al., 2004). Despite these results, no references report the combined use of both types of microorganisms on banana. According to previous results with other crops (Dhillion, 1992; Singh and Kapoor, 1998), this microbial interaction could be beneficial to bananas with the objective of developing sustainable banana agrosystems. The aim of the present study was to determine whether the combined inoculation of the fungus Glomus manihotis and a Bacillus spp. consortium based on three strains, previously described as plant growth-promoting rhizobacteria in other crops, was able to increase development and nutrient uptake of micropropagated banana plantlets during the nursery phase.

\section{MATERIALS AND METHODS}

\subsection{Biological material}

Micropropagated banana Musa acuminata Colla AAA, cv. 'Grande Naine' was provided by CULTESA (Cultivos Vegetales in vitro de Tenerife S.A.). Plantlets, measuring approximately $8 \pm 1 \mathrm{~cm}$ height with 3 fully developed leaves, were received in nutrient agar (Murashige and Skoog, 1962) and subsequently transplanted to $24-\mathrm{L}$ seed trays (20 plantlets/ tray), filled with a water steam-sterilized substrate mixture (1:1:1=soil:volcanic ash:peat TKS ${ }^{\circledR} 1$-Instant Sphagnum-Torf Klasmann Deilmann GmbH, Germany).

A Glomus manihotis strain (a collection isolate from Colombia) was cultured on tomato (Lycopersicon esculentum Mill.) plants. AMF inoculum consisted of rhizospheric soil containing pieces of mycorrhizal roots (74\% root colonization), hyphae and spores. $2 \mathrm{Kg} / \mathrm{seed}$ tray of inoculum were applied.

A Bacillus consortium containing strains INR7, T4 and IN 937b isolated and identified by Dr. Kloepper (Alabama, USA) and kept in TSB (Tryptone Soy Broth) with $20 \%$ glycerol was maintained at the Institut de Recerca i Tecnologia Agroalimentàries, IRTA (Spain). The bacterial inoculum was prepared after culturing the strains on Petri dishes with TSA (Tryptone Soy Agar), for two weeks. For each culture session, plates were incubated for $48 \mathrm{~h}$ at $25^{\circ} \mathrm{C}$. The bacterial inoculum consisted of a sterilized $\mathrm{NaCl}(0.85 \%)$ suspension containing approximately an equal amount of the three Bacillus strains. The inoculum concentration was approximately $10^{8} \mathrm{CFU}$ (colonies former units) $\mathrm{mL}^{-1}$ and was determined by using a viable versus absorbance at $600 \mathrm{~nm}$ curve for each Bacillus strain.

\subsection{Inoculation process and experimental design}

AMF was applied in the seed trays at the beginning of the experiment when plants were transferred from the in vitro flasks. Bacterial inoculation was carried out twice during the trial. A first dose $(5 \mathrm{~mL} /$ plant $)$ was applied 20 days after transplanting the in vitro plants to seed trays (i.e. 20 days after AMF inoculation). A second dose (20 mL/plant) took place 10 days after transplanting to individual pots.

The nursery phase lasted for 60 days ( 40 after the first dose of bacterial suspension) in which the plantlets were under an acclimatization tunnel with an ambient temperature of $25^{\circ} \mathrm{C}$ and a relative humidity of $90 \%$. Plantlets were irrigated with distilled water, $50-75 \mathrm{~mL}$ according to water requirements. Then, plants were transplanted to individual 4-L pots filled with a water steam-sterilized substrate mixture (1:1:1=soil:volcanic ash: peat TKS ${ }^{\circledR} 1$-Instant Sphagnum-Torf Klasmann Deilmann $\mathrm{GmbH}$, Germany). The substrate surface was then covered by a volcanic ash layer in order to keep the substrate humid. As was mentioned before, the second bacterial application $(20 \mathrm{~mL} /$ plant) was carried out 10 days after transplanting bananas to individual pots.

An experiment with 4 treatments lasting 135 days (after bacterial inoculation) was established: control, G. manihotis, Bacillus spp, and G. manihotis + Bacillus spp. Eight replicates were considered per treatment (32 plants) and plants were disposed in the greenhouse in a completely randomized design.

During this period, plants were grown under greenhouse conditions with an ambient temperature of $27-32{ }^{\circ} \mathrm{C}$ and a relative humidity of $70-80 \%$ and were irrigated with distilled water according to water requirements. Plants were fertilized according to the commercial standard fertilizer programmes. Once a month, plants were fertilized with Wuxal-Ca ${ }^{\circledR}$ (Argos Shering, Agrevo, S.A., Valencia) by using a dose of product of $3 \%$ (foliar application).

\subsection{Assessment of variables}

At harvest (135 days after bacterial inoculation), physical and nutritional parameters were assessed. The following physical parameters were measured: total fresh weight $(\mathrm{g})$ (aerial and root), aerial dry weight $(\mathrm{g})$, shoot length $(\mathrm{cm})$ and leaf area $\left(\mathrm{cm}^{2}\right)$. Leaf area was determined by using the surface measurer Li-COR, Inc., Lincoln, Nebraska, USA. Mod. Li-3100.

Macroelements, i.e. nitrogen, phosphorus and potassium, were determined on the shoots. The pseudostem and leaves of the banana plants were thoroughly washed in mild detergent, rinsed three times in distilled water, avoiding senescent or necrotic tissue, and prepared for foliar analysis. Samples were then dehydrated in a temperature-controlled fan-ventilated oven at $60{ }^{\circ} \mathrm{C}$ for 24 hours, ground in a ball mill and digested in wet acid (Jones et al., 1991), using nitric and perchloric acid. Analysis for all elements except nitrogen was carried out with a F586-587 Varian Liberty 220 inductively coupled plasma (ICP) emission spectrometer. Two readings were made per sample. Nitrogen content was determined according to the Kjeldahl procedure (Rund, 1984).

To assess mycorrhizal infection, a small root sample (5\% in fresh weight) of the whole root system was used to estimate the percentage of AM root infection. Samples were stained with $0.05 \%$ trypan blue in lactic acid (Phillips and Hayman, 1970) modified by the procedure described by Koske and Gemma (1989). The percentage of root colonization was determined on twenty $1-\mathrm{cm}$ sections of stained root, mounted on slides and examined with a light microscope as described by Brundett et al. (1985). 
Table I. Effect of the combined inoculation of G. manihotis and Bacillus spp. on micropropagated banana plantlets' development 135 days after bacterial inoculation.

\begin{tabular}{lcccc}
\hline Treatment & $\begin{array}{c}\text { Total fresh } \\
\text { weight } \\
(\mathbf{g})\end{array}$ & $\begin{array}{c}\text { Aerial dry } \\
\text { weight } \\
(\mathbf{g})\end{array}$ & $\begin{array}{c}\text { Shoot } \\
\text { length }(\mathbf{c m})\end{array}$ & $\begin{array}{c}\text { Leaf area } \\
\left(\mathbf{c m}^{\mathbf{2}}\right)\end{array}$ \\
\hline Control & $120.19 \mathrm{c}^{*}$ & $7.81 \mathrm{~b}$ & $50.4 \mathrm{~b}$ & $975.43 \mathrm{~b}$ \\
Bacillus spp. & $172.10 \mathrm{ab}$ & $11.19 \mathrm{ab}$ & $54.2 \mathrm{ab}$ & $1174.54 \mathrm{ab}$ \\
G. manihotis & $140.54 \mathrm{bc}$ & $8.67 \mathrm{ab}$ & $51.4 \mathrm{~b}$ & $1041.07 \mathrm{~b}$ \\
$\begin{array}{l}\text { G. manihotis }+ \\
\text { Bacillus } \text { spp. }\end{array}$ & $206.75 \mathrm{a}$ & $12.82 \mathrm{a}$ & $71.8 \mathrm{a}$ & $1365.16 \mathrm{a}$ \\
\hline
\end{tabular}

Means of 8 replicates. $*$ Within the same column, data followed by the same letter are statistically identical according to Tukey's Test $(P \leq$ $0.050)$.

\subsection{Statistical analysis}

All data were analyzed by ANOVA. Means were compared by Tukey's multiple range test $(P \leq 0.050)$. The analysis was performed by using Systat ${ }^{\circledR}$ 7.0.1. (SPSS. Inc ${ }^{\circledR}$ 1997).

\section{RESULTS AND DISCUSSION}

\subsection{Plant development}

Single application of either of the two microbes, or the combined inoculation of both of them, induced benefits in terms of banana development and nutrient uptake. However, plants treated with both microorganisms showed the highest significant increases. Dual inoculation of Glomus manihotis and Bacillus spp. significantly increased banana growth parameters. Values registered for all growth parameters were significantly higher for $G$. manihotis + Bacillus treatment as compared with the controls but did not differ from Bacillus spp. single treatment (Tab. I). Bacillus spp. inoculation resulted in a significant total fresh weight increase while no significant benefits were observed with the G. manihotis treatment, although all the growth parameters were higher than the controls. Total fresh weight in dual inoculated plants was almost double (1.7 times higher), compared with the controls. Aerial dry weight was also significantly increased by 1.5 times compared with the control treatment. Concerning shoot length and leaf area, plants inoculated with the arbuscular mycorrhizal fungus and Bacillus spp. showed significant increases (1.4 times higher), as compared with the controls.

\subsection{Nutrition}

Leaf mineral content was significantly increased by the combined application of the arbuscular mycorrhizal fungus and plant growth-promoting rhizobacteria (Fig. 1). Studying carefully each macroelement, it can be observed that $\mathrm{N}$ rates were $70 \%$ higher after combined inoculation compared with the controls. $\mathrm{P}$ and $\mathrm{K}$ levels were also significantly increased although differences were lower (64\% and $47 \%$ higher than the controls, respectively). Concerning microbial single treatments, either arbuscular mycorrhizal fungus or Bacillus were able in general

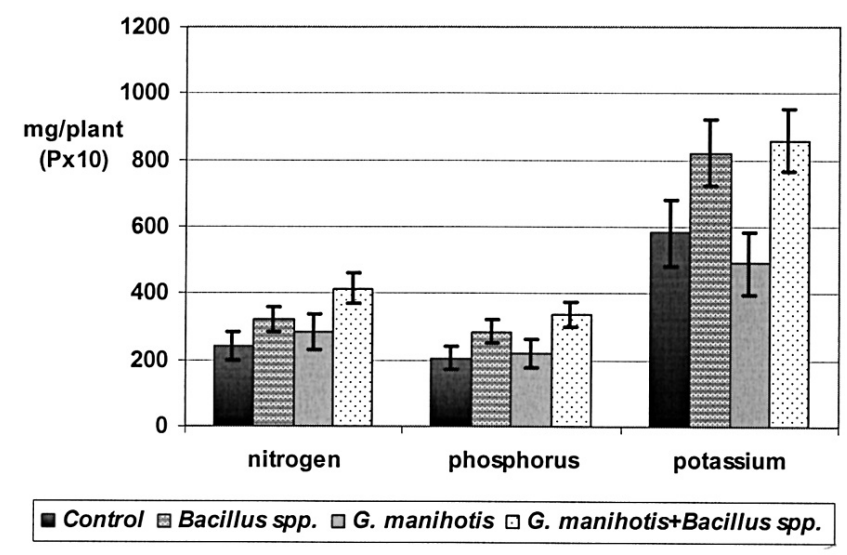

Figure 1. Effect of the combined inoculation of G. manihotis and Bacillus spp. on micropropagated banana plantlets' nutrition 135 days after bacterial inoculation.

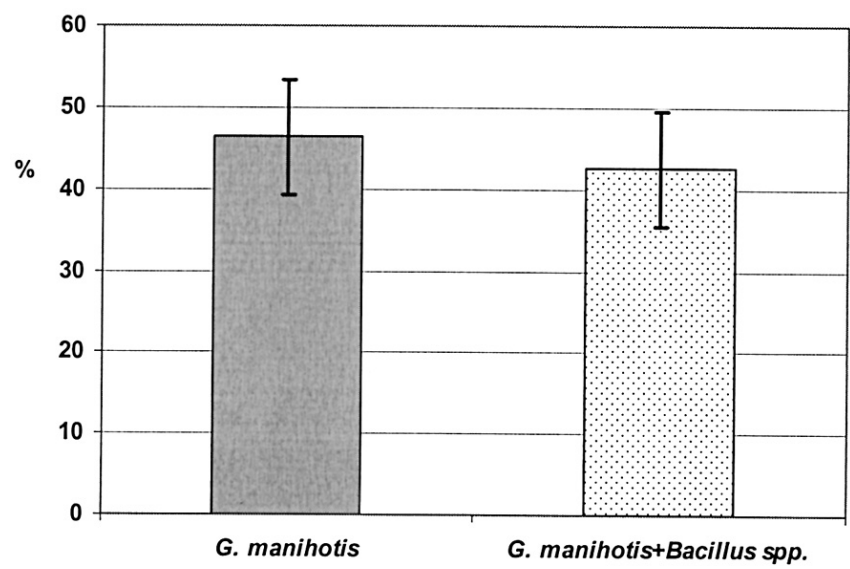

Figure 2. Mycorrhizal colonization root percentage at the end of the trial, 135 days after bacterial inoculation

to increase mineral uptake. Data registered in the Bacillus treatment showed significant increases compared with the controls in $\mathrm{P}$ and $\mathrm{K}$. In both parameters, these results did not differ from the Glomus-Bacillus treatment. On the other hand, increases detected in mycorrhizal plants were moderate (N and P). In any case, mycorrhizal bananas did not differ from the controls.

\subsection{Mycorrhizal colonization}

Mycorrhizal colonization levels between 40 and 50\% were detected at the end of the experiment (Fig. 2). Although bananas treated with bacteria showed a lower mycorrhizal colonization percentage, no significant differences could be observed between the two mycorrhizal treatments.

The interaction between Glomus manihotis and Bacillus spp. improved plant growth and mineral uptake of micropropagated banana plantlets. Benefits due to single inoculation of either arbuscular mycorrhizal fungi or plant growth-promoting rhizobacteria during the nursery phase have already been 
reported for this banana cultivar (Declerck et al., 2002; JaizmeVega et al., 2003, 2004). In these experiments, significant increases in plant development and mineral nutrition were detected after inoculation with any of these microorganisms. In the present work, although data from the arbuscular mycorrhizal fungus single treatment showed a marked improvement versus the controls, no statistical differences were observed. This is in contrast with the previous studies mentioned above, where the Glomus strain used and type of inoculum were different (Declerck et al., 2002; Jaizme-Vega et al., 2003). However, Declerck et al. (1995), working with several banana cultivars and arbuscular mycorrhizal fungi, observed different growth promotional effects depending on the banana cultivar and the Glomus strain. These authors detected a low promotional effect on 'Grande Naine' bananas inoculated with G. mosseae. On the other hand, Bacillus single inoculation significantly increased the total fresh weight and $\mathrm{K}$ content in shoots, which is in agreement with Jaizme-Vega et al. (2004).

Focusing on the combined effect of arbuscular mycorrhizal fungi and Bacillus spp., a significant increase was observed in all the growth parameters as compared with the controls (i.e. total fresh weight, aerial dry weight, shoot length and leaf area). Identically, leaf mineral content, i.e. N, P and $\mathrm{K}$, was also significantly higher as compared with the controls. Due to the absence of data available about this microbial interaction on banana, we compared our results with those obtained with other crops. Some authors have reported the synergistic beneficial effect in plant development promoted by the fungi-rhizobacteria association (Dhillion, 1992; Singh and Kapoor, 1998). Dual inoculation with both soil microorganisms also induced higher biomass and yield (Dhillion, 1992; Singh and Kapoor, 1998), and even higher nutrient uptake (Singh and Kapoor, 1998). However, diversity in the response depending on the microbial combination has also been described (Ravnskov and Jakobsen, 1999). This diversity in response can be explained according to the high specificity involved in the rhizosphere microbial interactions (Azcón, 1989; Kloepper, 1996).

In this experiment, no negative effect of plant growth-promoting rhizobacteria on the mycorrhizal symbiosis establishment was detected, since the colonization percentage in roots was statistically identical both with Bacillus spp. and without them. No adverse effect of plant growth-promoting rhizobacteria on mycorrhizal symbiosis has been previously reported (Attia, 1999). Also, under some conditions, plant growth-promoting rhizobacteria are able to promote fungal spore germination and germinative tube elongation (Andreucci et al., 1999) or even enhance mycorrhizal hyphae density (Ravnskov and Jakobsen, 1999). Nevertheless, the opposite situation has also been described (Germida and Walley, 1997). The reasons for this phenomenon must be observed again under the high specificity of microbial interactions (Azcón, 1989; Kloepper, 1996).

\section{CONCLUSION}

In conclusion, our results confirm the suitability of the combined application of arbuscular mycorrhizal fungi and plant growth-promoting rhizobacteria to improve banana growth and nutrition during the nursery phase. The suitable management of these symbionts represents a feasible strategy for the micropropagation process in the banana-producing regions: micropropagated plants would be carried to the field with an established microbial rhizosphere which would contribute to an easier adaptation to field conditions. However, due to the high specificity in terms of functional compatibility involved in these types of interactions, a previous screening to select the best microbe-host plant combination should be done in order to optimize the results. The absence of references about this microbial interaction in banana allows us to propose for the first time this method for the improvement of sustainability of banana cropping systems.

Acknowledgements: The authors would like to thank A.R. Socorro Monzón from ICIA (Dpto. Suelos y Riegos) for foliar mineral analysis. This work was economically supported by the European Commission (INCO-DC ERBIC $18 *$ CT970208)

\section{REFERENCES}

Andreucci F., Fusconi A., Gamalero E., Piras R., Repetto O., Sampó S., Trotta A., Martinotti M.G., Berta G. (1999) Reduction of the chemical inputs in a vegetable crop by the use of beneficial rhizospheric microorganisms, INCO-DC, Second Annual Report.

Attia M. (1999) The efficiency improvements of mineral fertilizers used and maize yield by Arbuscular Mycorrhizal Fungus and Plant Growth-Promoting Rhizobacteria, Ann. Agricul. Sci. Cairo 44, 41-53.

Azcón R. (1989) Selective interaction between free-living rhizosphere bacteria and vesicular-arbuscular mycorrhizal fungi, Soil Biol. Biochem. 25, 1037-1042.

Barea J.M., Azcón-Aguilar C., Azcón R. (1997) Interactions between mycorrhizal fungi and rhizosphere microorganisms within the context of sustainable soil-plant systems, in: Gange A.C., Brown V.K. (Eds.), Multitrophic interactions in terrestrial systems, Blackwell Science, Oxford, pp. 65-77.

Barea J.M., Gryndler M., Lemanceau P., Schüepp H., Azcón R. (2002) The rhizosphere of mycorrhizal plants, in: Gianinazzi S., Schüepp H., Barea J.M., Haselwandter K. (Eds.), Mycorrhizal Technology in Agriculture: from Genes to Bioproducts, Birkhäuser Verlag, Switzerland, pp. 1-18.

Brundett M.S., Piche Y., Peterson R.L. (1985) A development study of the early stages in vesicular-arbuscular mycorrhizal formation, Can. J. Bot. 63, 184-194.

Caesar A.J., Burr T.J. (1987) Growth promotion of apple seedlings and rootstocks by specific strains of bacteria, Phytopathol. 77, 15831588 .

Damasco O.P., Smith M.K., Adkins S.W., Hetherington S.E., Godwin I.D. (1998) Identification and characterization of dwarf off-types from micropropagated Cavendish banana, Acta Hort. 490, 79-84.

Declerck S., Plenchette C., Strullu D.G. (1995). Mycorrhizal dependency of banana (Musa acuminata, AAA group) cultivar, Plant Soil $176,183-187$.

Declerck S., Risede J.M., Delvaux B. (2002) Greenhouse response of micropropagated bananas inoculated with in vitro monoxenically produced arbuscular mycorrhizal fungi, Sci. Hort. 93, 301-309.

Dhillion S.S. (1992) Dual inoculation of pre-transplant stage Oryza sativa $\mathrm{L}$. plants with indigenous vesicular-arbuscular mycorrhizal fungi and fluorescens Pseudomonads spp., Biol. Fert. Soils 13, $147-151$.

George E.F. (1996) Plant propagation by tissue culture, Part 2, In practise, Exegetics, Basingstoke. 
Germida J.J., Walley F.L. (1997) Plant growth promoting rhizobacteria alter rooting patterns and arbuscular mycorrhizal fungi colonization of field-grown spring wheat, Biol. Fert. Soils 23, 113-120.

Kloepper J.W. (1992) Plant Growth-Promoting Rhizobacteria as Biological Control Agents, in: Metting F.B., Dekker M. (Eds.), Soil Microbial Ecology, Applications in Agriculture, Forestry and Environmental Management, Dekker M., Inc., New York, USA, pp. $255-274$.

Kloepper J.W. (1996) Host specifity in microbe-microbe interactions, BioScience 46, 406-409.

Jaizme-Vega M.C., Rodríguez-Romero A.S., Marín Hermoso S., Declerck S. (2003) Growth of micropropagated bananas colonized by root-organ culture produced arbuscular mycorrhizal fungi entrapped in Ca-alginate beads, Plant Soil 254, 329-335.

Jaizme-Vega M.C., Rodríguez-Romero A.S., Piñero Guerra M.S. (2004) Potential use of rhizobacteria from the Bacillus genus to stimulate the plant growth of micropropagated banana, Fruits 59, 83-90.

Jones J.B., Benjamin B., Mills H.A. (1991) Plant Analysis Handbook, 1 Methods of Plant Analysis and Interpretation, Micro-Macro Publishing, Athens, GA, $213 \mathrm{p}$.

Koske R.E., Gemma J.M. (1989) A modified procedure for staining roots to detect VA mycorrhizas, Mycol. Res. 92, 486-505.

Murashige T., Skoog F. (1962) A revised medium for rapid growth and bioassays with tobacco tissues culture, Physiol. Plant. 15, 473497.

Nowak J. (1998) Benefits of in vitro biotization of plant tissue cultures with microbial inoculants, In vitro Cell Dev. Plant 34, 122-130.
Phillips J.M., Hayman D.S. (1970) Improve procedures for cleaning roots and stain parasitic and vesicular-arbuscular fungi for rapid assessment of infection, Trans. Br. Mycol. Soc. 55, 158-161.

Polonenko D.R., Scher F.M., Kloepper J.W., Singleton C.A., Laliberté M., Zaleska I. (1987) Effects of root colonizing bacteria on inoculation of soybean roots by Bradyrhizobium japonicum, Can. J. Microbiol. 33, 498-503.

Rai M.K. (2001) Current advances in mycorrhization in micropropagation, In vitro Cell Cev. Plant 37, 158-167.

Ravnskov J., Jakobsen I. (1999) Effects of Pseudomonas fluorescens DF57 on growth and P uptake of two arbucular mycorrhizal fungi in symbiosis with cucumber, Mycorrhiza 8, 329-334.

Rund R.C. (1984) Fertilizers, in: Williams S. (Ed.), Official Methods of Analysis of the Association of Official Analytic Chemist, 14th ed., pp. 8-37.

Singh S., Kapoor K.K. (1998) Effects of inoculation of phosphate-solubilizing microorganisms and an arbuscular mycorrhizal fungus on mungbean grown under natural soil conditions, Mycorrhiza 7, 249-253.

Smith S.E., Read D.J. (1997) Mycorrhizal symbiosis, Academic Press, London.

Vestberg M., Cassells A.C., Schubert A., Cordier C., Gianinazzi S. (2002) Arbuscular mycorrhizal fungi and micropropagation of high value crops, in: Gianinazzi S., Schüepp H., Barea J.M., Haselwandter K. (Eds.), Mycorrhizal Technology in Agriculture: from Genes to Bioproducts, Birkhäuser Verlag, Switzerland, pp. 223-233. 